\title{
REDISCUTINDO A EDUCAÇÃO ESPECIAL NA EDUCAÇÃO SUPERIOR: o mapeamento dos documentos legais
}

\author{
Paula Lidiane Cezar PEREIRA ${ }^{1}$ \\ Morgana CHRISTMANN ${ }^{2}$ \\ Sílvia Maria de Oliveira PAVÃO ${ }^{3}$
}

\begin{abstract}
Resumo
Este estudo tem por objetivo mapear os documentos normativos (políticas públicas e legislações) que garantem o ingresso e a permanência do público-alvo da Educação Especial (pessoas com deficiência) no Ensino Superior. O método da investigação, do tipo documental, foi caracterizado pela análise categorial clássica, e os dados foram coletados no sítio eletrônico do Ministério da Educação. Constatou-se que os documentos que buscam orientar e regular a Educação Especial, no contexto da Educação Superior, ainda não são suficientes, pois as únicas leis que tratam da Educação Especial na Educação Superior são: Lei Brasileira de Inclusão, Lei n ${ }^{\circ}$ 13.146/15 e a Lei no 13.409/16, sendo esta última a que segura a reserva de vagas. Em conclusão, a reserva de vagas em Instituições de Ensino Superior não é a garantia da equidade, integralidade e qualidade na permanência e na conclusão dos cursos, portanto, é preciso ampliar a discussão.
\end{abstract}

Palavras-chave: Público-alvo da Educação Especial. Educação Superior. Documentos Legais.

\footnotetext{
${ }^{1}$ Graduada em Educação Especial. Especialista em Gestão Edcacional. Mestranda em Educação na Universidade Federal de Santa Maria. Integrante do Grupo de Pesquisa em Educação, Saúde e Inclusão GEPEDUSI.

E-mail: paulapereiracesar@gmail.com

${ }^{2}$ Doutora em Educação pela Universidade Federal de Santa Maria, Integrante do Grupo de Pesquisa em Educação, Saúde e Inclusão (GEPEDUSI) da Universidade Federal de Santa Maria, Docente da Universidade Franciscana (Santa Maria-RS).

E-mail: fisiomorganac@gmail.com

${ }^{3}$ Phd. em Educação pela Universidade Federal do Rio Grande do Sul e Doutora em Educação pela Universidad Autonoma de Barcelona (ES), Líder do Grupo de Pesquisa em Educação, Saúde e Inclusão (GEPEDUSI) da Universidade Federal de Santa Maria e Docente do Programa de PósGraduação em Educação da Universidade Federal de Santa Maria.

E-mail: silviamariapavao@gmail.com
} 


\title{
REAPPROACHING SPECIAL EDUCATION IN HIGHER EDUCATION: mapping the legal documentation
}

\author{
Paula Lidiane Cezar PEREIRA \\ Morgana CHRISTMANN \\ Sílvia Maria de Oliveira PAVÃO
}

\begin{abstract}
This study aims to map the normative documents (public policies and legislation) that guarantee the entry and permanence of subjects in need of Special Education (people with disabilities) in Higher Education. Through an archival research following the methodology of classical categorical analysis, the data was collected from the website of the Brazilian Ministry of Education. It was found that the documents that seek to guide and regulate Special Education in the context of Higher Education are not yet sufficient, since the only laws on Special Education in Higher Education are: the Brazilian Inclusion Law, Law 13.146/15 and Law 13.409/16, the latter being the one which determines the reservation of slots. In conclusion, the reserved slots in Brazilian Higher Education Institutions do not guarantee equity, completeness and quality in the permanence and conclusion of courses, making it necessary to broaden the discussion.
\end{abstract}

Keywords: Subjects of Special Education. Higher Education. Legal Documentation. 


\section{Introdução}

O público-alvo da Educação Especial (BRASIL, 2008, 2015), reconhecido como as pessoas com deficiência, autismo e altas habilidades/superdotação, esteve exposto aos diversos tratamentos, uma vez que essas pessoas eram consideradas como doentes que não tinham perspectivas de reabilitação. Com o passar dos anos, com o investimento de movimentos sociais - organizados a partir das próprias pessoas com deficiência, que lutavam por seus direitos -, bem como uma compreensão ampliada sobre a deficiência, desvinculando-a da doença, novas estratégias e ações foram sendo desenvolvidas para a garantia de direitos humanos (JANUZZI, 2004). Desse modo, na atualidade, essa população vem conseguindo ter acesso ao Ensino Superior, fato concretizado a partir de políticas públicas de ingresso, formação e permanência.

Nessa configuração, uma abordagem recorrente entre os pesquisadores que se dedicam ao processo de inclusão de pessoas com deficiência no Ensino Superior trata dos entraves envolvidos com a formação humana e técnica nesse nível de ensino, considerando as diferentes dificuldades impostas por um sistema que não foi estruturado para responder por tais necessidades. Assim sendo, políticas públicas e legislações devem ofertar o suporte necessário para que os profissionais da educação possam exercer suas atividades voltadas ao paradigma da inclusão vigente. A inclusão educacional, nesse contexto, é entendida a partir da Declaração de Educação para Todos (WCEFA, 1990), que busca organizar o acesso equitativo e de qualidade à educação para todas as pessoas, independentemente de suas características, dificuldades, religião e cultura.

Diante dessa realidade que aponta para diferentes interfaces, questiona-se: quais são as políticas públicas e legislações do Ensino Superior que garantem o acesso e a permanência do público-alvo da Educação Especial nesse nível de ensino? As reflexões, aqui suscitadas, pautam-se nos discursos produzidos pelas legislações e políticas que debatem a temática, especialmente, nos últimos 30 anos. Portanto, o objetivo deste artigo consiste em mapear os documentos normativos (políticas públicas e legislações) que garantem o ingresso e a permanência do público-alvo da Educação Especial (pessoas com deficiência) no Ensino Superior.

Antes de dar seguimento à reflexão proposta por esta pesquisa, são apresentados os conceitos que definem o objeto de estudo, conquanto documentações legais: políticas públicas, leis e normas, para posteriormente haver reflexão sobre as legislações. As políticas públicas são um conjunto de decisões e ações oriundas dos Governos e destinadas à resolução de problemas políticos, elaboradas no sentido de enfrentar um problema público (RUA, 1998; SECCHI, 2012; SOUZA, 2006). Para Sousa e Silva (2016, p. 9), as Políticas Públicas abrangem "[...] toda e qualquer ação de responsabilidade do Estado, que visa o bem-estar social do povo, tendo como sustentáculo os órgãos políticos e as entidades da sociedade civil”. Portanto, são delas que decorrem as "normas, as regras e as leis de um 
país” (SOUSA; SILVA, 2016, p. 9). Esse entendimento acerca do conceito de política pública e suas afetações na sociedade compreendem todos os aspectos que envolvem o papel do estado e a legislação (MOLINA; RODRIGUES, 2020; PEREIRA, 2020).

Ainda sobre a compreensão de Políticas Públicas, Torrens (2013, p. 189), refere que as políticas são os polos norteadores do poder público, diretrizes, procedimentos e regras que "determinam as relações entre o Estado e os atores sociais a que se destinam as aplicações de recursos públicos e os benefícios sociais, concretizados em programas, financiamentos e leis”, as quais reproduzem as prioridades de cada governo.

As leis, por sua vez, podem ser criadas a partir de políticas públicas que despertam necessidades antes não percebidas pelo Estado. Dessa maneira, as leis são um conjunto de normas que: tem valor jurídico, nos diferentes espaços do território nacional e internacional; e ofertam estabilidade governamental e segurança jurídica para as relações estabelecidas entre as pessoas, as instituições públicas e privadas e as empresas (DINIZ, 2012). São, por conseguinte, normas regulamentares que devem ser seguidas pela sociedade, em suas diferentes instâncias.

\section{Método}

Esta pesquisa diz respeito a um estudo documental, o qual "baseia-se em materiais que não receberam ainda um tratamento analítico ou que podem ser reelaborados de acordo com os objetivos da pesquisa" (PRODANOV; FREITAS, 2013, p. 66). O material de análise é constituído pelos seguintes documentos legais: leis e políticas públicas sobre a inclusão do público-alvo da Educação Especial, tratado a partir da Política Nacional de Educação Especial, na Perspectiva da Educação Inclusiva e Lei Brasileira de Inclusão (BRASIL, 2008, 2015), ofertando ênfase àqueles que tratam da educação do público em pauta, ao nível da Educação Superior.

Para tanto, foram selecionadas legislações federais e políticas públicas vinculadas ao ingresso na Educação Superior. A fonte para a coleta dos dados foi o sítio eletrônico do Ministério da Educação. Os documentos selecionados buscaram responder ao objetivo (Quadro 1), de forma que, em todos eles, foram encontrados elementos relativos ao ingresso e à permanência dos estudantes com deficiência no nível de ensino em questão. As categorias foram criadas a priori, identificando, assim, por meio das palavras-chave: "público alvo", "legislações” e "educação especial”, aqueles que compõem o grupo da Educação Especial em foco neste estudo, apontando, posteriormente, como se dá o processo de ingresso na Educação Superior até a respectiva conclusão do curso, a partir das legislações e políticas públicas.

A análise dos materiais foi realizada a partir da análise de conteúdo clássica, que consiste em "[...] uma operação ou um conjunto de operações visando representar o 
conteúdo de um documento sob uma forma diferente do original, a fim de facilitar, num estado ulterior, a sua consulta e a sua referenciação” (BARDIN, 2011, p. 51).

Desse modo, por meio da leitura flutuante e da aproximação com as informações contidas nos documentos, tendo como base o objetivo deste artigo - qual seja: mapear os documentos normativos (políticas públicas e legislações) que garantem o ingresso e a permanência do público-alvo da Educação Especial (pessoas com deficiência) no Ensino Superior -, as categorias criadas a priori, foram sendo desenvolvidas. São elas, portanto: Público-alvo da Educação Especial; Legislações federais da Educação Superior: do Ingresso à conclusão.

\section{Resultados e discussão}

A documentação legal (legislações e políticas) vinculada à da educação das pessoas com deficiência na Educação Superior, desde as primeiras citações nos documentos legais, foram analisadas para responder ao objetivo deste estudo (Quadro 1).

Quadro 1 - Documentos sobre a inclusão do público da educação especial no Ensino Superior

\begin{tabular}{|c|c|c|}
\hline POLÍTICA & $\begin{array}{c}\text { ANO DE } \\
\text { PUBLICAÇÃO }\end{array}$ & OBJETIVO \\
\hline $\begin{array}{l}\text { Lei de Diretrizes e Bases da } \\
\text { Educação Nacional }\end{array}$ & 1961 & $\begin{array}{l}\text { Aponta o direito dos “excepcionais” } \\
\text { à educação, preferencialmente } \\
\text { dentro do sistema geral de ensino. }\end{array}$ \\
\hline $\begin{array}{l}\text { Política Nacional de Educação } \\
\text { Especial }\end{array}$ & 1994 & $\begin{array}{l}\text { Orientando o processo de } \\
\text { ‘integração instrucional’ que } \\
\text { condiciona o acesso às classes } \\
\text { comuns do ensino regular àqueles } \\
\text { que “[...] possuem condições de } \\
\text { acompanhar e desenvolver as } \\
\text { atividades curriculares programadas } \\
\text { do ensino comum, no mesmo ritmo } \\
\text { que os alunos ditos normais” } \\
\text { (BRASIL, 1994, p. 19). }\end{array}$ \\
\hline $\begin{array}{c}\text { Lei de Diretrizes e Bases da } \\
\text { Educação Nacional, Lei n }{ }^{\circ} \\
\text { 9.394/96 }\end{array}$ & 1996 & $\begin{array}{l}\text { Artigo } 58^{\circ} \text {. Entende-se por educação } \\
\text { especial, para os efeitos desta Lei, a } \\
\text { modalidade de educação escolar } \\
\text { oferecida preferencialmente na rede } \\
\text { regular de ensino, para educandos } \\
\text { com deficiência, transtornos globais } \\
\text { do desenvolvimento e altas } \\
\text { habilidades ou superdotação. } \\
\text { Artigo 59. Preconiza que os } \\
\text { sistemas de ensino devem assegurar } \\
\text { aos alunos currículo, métodos, } \\
\text { recursos e organização específicos } \\
\text { para atender às suas necessidades; } \\
\text { assegura a terminalidade específica } \\
\text { àqueles que não atingiram o nível } \\
\text { exigido para a conclusão do ensino } \\
\text { fundamental, em virtude de suas } \\
\text { deficiências e; a aceleração de }\end{array}$ \\
\hline
\end{tabular}




\begin{tabular}{|c|c|c|}
\hline POLÍTICA & $\begin{array}{c}\text { ANO DE } \\
\text { PUBLICAÇÃO }\end{array}$ & OBJETIVO \\
\hline & & $\begin{array}{l}\text { estudos aos superdotados para } \\
\text { conclusão do programa escolar. } \\
\text { Artigo } 60^{\circ} \text {. Parágrafo único: O poder } \\
\text { público adotará, como alternativa } \\
\text { preferencial, a ampliação do } \\
\text { atendimento aos educandos com } \\
\text { deficiência, transtornos globais do } \\
\text { desenvolvimento e altas habilidades } \\
\text { ou superdotação na própria rede } \\
\text { pública regular de ensino, } \\
\text { independentemente do apoio às } \\
\text { instituições previstas neste artigo. }\end{array}$ \\
\hline $\begin{array}{c}\text { Decreto nº 3.298, Política } \\
\text { Nacional para a Integração da } \\
\text { Pessoa Portadora de Deficiência }\end{array}$ & 1999 & $\begin{array}{l}\text { Define a Educação Especial como } \\
\text { uma modalidade transversal a todos } \\
\text { os níveis e modalidades de ensino, } \\
\text { enfatizando a atuação complementar } \\
\text { da educação especial ao ensino } \\
\text { regular. }\end{array}$ \\
\hline Lei $n^{\circ} 10.436$ & 2002 & $\begin{array}{c}\text { Dispõe sobre a Língua Brasileira de } \\
\text { Sinais - Libras e dá outras } \\
\text { providências. }\end{array}$ \\
\hline Portaria $\mathrm{n}^{\circ} 2.678$ & 2002 & $\begin{array}{l}\text { Aprova diretriz e normas para o uso, } \\
\text { o ensino, a produção e a difusão do } \\
\text { Sistema Braille em todas as } \\
\text { modalidades de ensino, } \\
\text { compreendendo o projeto da Grafia } \\
\text { Braile para a Língua Portuguesa e a } \\
\text { recomendação para o seu uso em } \\
\text { todo o território nacional. }\end{array}$ \\
\hline Portaria $\mathrm{n}^{0} 3.284$ & 2003 & $\begin{array}{l}\text { Dispõe sobre requisitos de } \\
\text { acessibilidade de pessoas portadoras } \\
\text { de deficiências, para instruir os } \\
\text { processos de autorização e de } \\
\text { reconhecimento de cursos, e de } \\
\text { credenciamento de instituições. }\end{array}$ \\
\hline Decreto $n^{\circ} 5.296$ & 2004 & $\begin{array}{l}\text { Regulamentou as leis } \mathrm{n}^{\circ} 10.048 / 00 \text { e } \\
\mathrm{n}^{\circ} \text { 10.098/00, estabelecendo normas } \\
\text { e critérios para a promoção da } \\
\text { acessibilidade às pessoas com } \\
\text { deficiência ou com mobilidade } \\
\text { reduzida. }\end{array}$ \\
\hline Decreto $n^{\circ} 5.626$ & 2005 & $\begin{array}{l}\text { Regulamenta a Lei } \mathrm{n}^{\circ} \text { 10.436/2002, } \\
\text { visando a inclusão dos alunos } \\
\text { surdos, dispõe sobre a inclusão da } \\
\text { Libras como disciplina curricular, a } \\
\text { formação e a certificação de } \\
\text { professor, instrutor e } \\
\text { tradutor/intérprete de Libras, o } \\
\text { ensino da Língua Portuguesa como } \\
\text { segunda língua para alunos surdos e } \\
\text { a organização da educação bilíngue } \\
\text { no ensino regular. }\end{array}$ \\
\hline Lei $n^{\circ} 11.096$ & 2005 & $\begin{array}{l}\text { Institui o Programa Universidade } \\
\text { para Todos - PROUNI, regula a } \\
\text { atuação de entidades beneficentes de } \\
\text { assistência social no ensino superior; } \\
\text { altera a Lei no } 10.891 \text {, de } 9 \text { de julho } \\
\text { de } 2004 \text {, e dá outras providências. }\end{array}$ \\
\hline
\end{tabular}




\begin{tabular}{|c|c|c|}
\hline POLÍTICA & $\begin{array}{c}\text { ANO DE } \\
\text { PUBLICAÇÃO }\end{array}$ & OBJETIVO \\
\hline $\begin{array}{c}\text { Plano Nacional de Educação em } \\
\text { Direitos Humanos }\end{array}$ & 2007 & $\begin{array}{l}\text { O PNEDH se organiza para ofertar } \\
\text { subsídios para o estabelecimento de } \\
\text { concepções, princípios, objetivos, } \\
\text { diretrizes e linhas de ação, } \\
\text { contemplando cinco grandes eixos } \\
\text { de atuação: Educação Básica; } \\
\text { Educação Superior; Educação Não- } \\
\text { Formal; Educação dos Profissionais } \\
\text { dos Sistemas de Justiça e Segurança } \\
\text { Pública e Educação e Mídia. } \\
\text { As linhas gerais de ação estabelecem } \\
\text { que o PNEDH deve: Promover a } \\
\text { produção e disseminação de dados e } \\
\text { informações sobre educação em } \\
\text { direitos humanos por diversos meios, } \\
\text { de modo a sensibilizar a sociedade e } \\
\text { garantir acessibilidade às pessoas } \\
\text { com deficiências. }\end{array}$ \\
\hline $\begin{array}{l}\text { Política Nacional de Educação } \\
\text { Especial na Perspectiva da } \\
\text { Educação Inclusiva }\end{array}$ & 2008 & $\begin{array}{l}\text { Garantir a transversalidade da } \\
\text { Educação Especial desde a Educação } \\
\text { Infantil até a Educação Superior; } \\
\text { Garantir o acesso, a participação e a } \\
\text { aprendizagem dos estudantes com } \\
\text { deficiência, transtornos globais do } \\
\text { desenvolvimento e altas } \\
\text { habilidades/superdotação nas escolas } \\
\text { regulares, orientando os sistemas de } \\
\text { ensino para promover respostas às } \\
\text { necessidades educacionais. } \\
\text { Na Educação Superior, a Educação } \\
\text { Especial se efetiva por meio de } \\
\text { ações que promovam o acesso, a } \\
\text { permanência e a participação dos } \\
\text { estudantes. Essas ações envolvem o } \\
\text { planejamento e a organização de } \\
\text { recursos e serviços para a promoção } \\
\text { da acessibilidade arquitetônica, nas } \\
\text { comunicações, nos sistemas de } \\
\text { informação, nos materiais didáticos e } \\
\text { pedagógicos, que devem ser } \\
\text { disponibilizados nos processos } \\
\text { seletivos e no desenvolvimento de } \\
\text { todas as atividades que envolvam o } \\
\text { ensino, a pesquisa e a extensão. }\end{array}$ \\
\hline Decreto no 6.949 & 2009 & $\begin{array}{l}\text { Promulga a Convenção Internacional } \\
\text { sobre os Direitos das Pessoas com } \\
\text { Deficiência, entre eles o direito à } \\
\text { educação em todos os níveis de } \\
\text { ensino. }\end{array}$ \\
\hline Lei n 13.146 & 2015 & $\begin{array}{l}\text { Institui a Lei Brasileira de Inclusão } \\
\text { da Pessoa com Deficiência (Estatuto } \\
\text { da Pessoa com Deficiência). }\end{array}$ \\
\hline Lei n ${ }^{\circ} 13.234$ & 2015 & $\begin{array}{c}\text { Altera a Lei n }{ }^{\circ} 9.394 \text {, de } 20 \text { de } \\
\text { dezembro de 1996, para dispor sobre } \\
\text { a identificação, o cadastramento e o } \\
\text { atendimento, na Educação Básica e } \\
\text { na Educação Superior, de alunos } \\
\text { com altas habilidades ou } \\
\text { superdotação. }\end{array}$ \\
\hline
\end{tabular}




\begin{tabular}{|c|c|c|}
\hline POLÍTICA & $\begin{array}{c}\text { ANO DE } \\
\text { PUBLICAÇÃo }\end{array}$ & OBJETIVO \\
\hline & & \\
\hline Lei n ${ }^{\circ} 13.409$ & 2016 & $\begin{array}{c}\text { Altera a Lei } \mathrm{n}^{\circ} \text { 12.711, de } 29 \text { de } \\
\text { agosto de 2012, para dispor sobre a } \\
\text { reserva de vagas para pessoas com } \\
\text { deficiência. }\end{array}$ \\
\hline
\end{tabular}

Fonte: elaborado pela autora, 2019.

As legislações e políticas referenciadas mostram que houve um movimento legislatório para a garantia do direito à educação para pessoas com deficiência ao longo dos anos, englobando a Educação Superior. Entretanto, apesar dessa dinâmica, somente recentemente as pesquisas no campo da Educação Especial passaram a direcionar o olhar para a Educação Superior, uma vez que estudantes público-alvo da Educação Especial estão chegando às universidades e, por conseguinte, exigindo o atendimento de suas necessidades, conforme a legislação busca garantir (CHRISTMANN, 2019).

\section{O público-alvo da educação especial}

Tendo como referência inicial a Política Nacional de Educação Especial na Perspectiva da Educação Inclusiva (2008), documento que compila indicativos de políticas de inclusão, considera-se o público-alvo da Educação Especial: as pessoas com deficiência, altas habilidades/superdotação e transtorno global do desenvolvimento (autismo).

Segundo a Classificação Internacional de Incapacidade, Funcionalidade e Saúde (CIF), o termo deficiência é entendido como "problemas nas funções ou nas estruturas do corpo, tais como, um desvio importante ou uma perda”, que, por conseguinte, acarretam em dificuldades frente à sociedade e ao contexto em que vivem (OMS, 2004, p. 9). Por isso, além dos impedimentos das mais diversas ordens atinentes à condição que as alterações nas funções ou estruturas do corpo impõem à deficiência, essas pessoas sofrem influência das interações que podem se apresentar como barreiras para o pleno desenvolvimento e participação na sociedade. Diante disso, as pessoas com deficiência são consideradas a partir das barreiras que impedem "[...] sua participação plena e efetiva na sociedade em igualdade de condições com as demais pessoas” (BRASIL, 2015). Desse modo, entende-se que a deficiência une aspectos biológicos e sociais, considerando que a sociedade não está estruturada para atender as necessidades diversas que caracterizam cada pessoa.

A concepção de deficiência é tratada por Christmann (2019), a partir de uma abordagem que engloba os conceitos que perpassam a saúde e a educação, envolvidos com a deficiência. A autora dispõe que tanto a concepção que envolve alterações nas funções e estruturas do corpo quanto as barreiras sociais constituem a pessoa com deficiência, por isso a deficiência precisa ser entendida como uma condição que não impede as pessoas de executar qualquer atividade, mas que caracteriza as particularidades de cada um. 
Os Transtornos Globais do Desenvolvimento (TGD) englobaram os transtornos: Transtorno Autista, Transtorno de Asperger, Transtorno de Rett, Transtorno Desintegrativo da Infância e Transtorno Global do Desenvolvimento Sem Outra Especificação. Tais transtornos eram, primeiramente, diagnosticados na infância e, muitas vezes, incluíam a deficiência intelectual associada a sintomas relacionados à interação social, à comunicação e à comportamentos estereotipados pela falta de parâmetros diagnósticos (SCHIMDT, 2017).

Por gerar muitos impasses entre clínicos, o TGD foi substituído pelo Transtorno do Espectro Autista (TEA). O TEA, conforme o Manual Diagnóstico e Estatístico de Transtornos Mentais (DSM-V), “[...] descreve as características centrais do autismo como pertencentes a duas dimensões: a comunicação social e os comportamentos”, e o “TGD era baseado em uma tríade de características na interação social, comunicação e comportamentos” (SCHIMIDT, 2017, p. 3). Assim, o autismo passa a ser entendido atualmente a partir de um espectro, o Transtorno do Espectro Autista (TEA).

O DSM-V é uma referência internacional amplamente conhecida e difundida tanto na área da Educação quanto da Saúde, e corrobora com as observações feitas por Schmitt (2016) sobre a definição do autismo. Segundo Schmitt et al. (2016, p. 223 apud APA, 2013), o autismo é definido como

um conjunto de transtornos neurodesenvolvimentais de causas orgânicas, caracterizado por dificuldades de interação e comunicação que podem vir associadas a alterações sensoriais, comportamentos estereotipados e/ou interesses restritos. Sua manifestação é muito diversa e seus sinais, embora comumente presentes na infância, podem surgir somente quando as demandas sociais extrapolarem os limites de suas capacidades.

Já as pessoas com altas habilidades/superdotação, de acordo com a Política Nacional de Educação Especial na Perspectiva da Educação Inclusiva (BRASIL, 2008), apresentam potencial elevado em todas as habilidades ou em alguns aspectos, como intelectualmente e academicamente, potencial de liderança, psicomotricidade desenvolvida e habilidade em artes, “além de apresentar grande criatividade, envolvimento na aprendizagem e realização de tarefas em áreas de seu interesse” (BRASIL, 2008, p. 9).

A presença desses estudantes nas salas de aula demanda uma mudança na prática pedagógica, com o objetivo de possibilitar a aprendizagem de todos, independentemente de suas dificuldades. Dessa forma, assim como na Educação Básica, as Instituições de Ensino Superior (IES) deveriam ofertar apoio pedagógico tanto aos estudantes quanto aos docentes que se deparam com essa nova realidade. Essa falta de familiarização com uma prática pedagógica inclusiva não se restringe às necessidades do público-alvo da Educação Especial, mas se direciona, também, à formação de professores universitários com falta de conhecimento em didática, especialmente, o que poderia ofertar melhores condições de conduzir a aprendizagem dos estudantes (PIMENTA; ANASTASIOU, 2014). 
Desse modo, a garantia de ingresso dos estudantes público-alvo da Educação Especial não é suficiente, haja vista que nem todas as IES estão preparadas para atender as demandas que as pessoas com deficiência têm no seu processo de formação, especialmente no que tange à técnica, aos processos de aprendizagem e quanto à acessibilidade em suas diversas faces: atitudinal, arquitetônica, metodológica, programática, instrumental e comunicacional (SASSAKI, 2005). Sendo assim, a "acessibilidade é direito que garante à pessoa com deficiência ou com mobilidade reduzida viver de forma independente e exercer seus direitos de cidadania e de participação social” (BRASIL, 2015, art. 53).

Considerando que a universidade é um espaço potente para a adoção de atitudes e estratégias voltadas à acessibilidade, a partir do conhecimento que se produz nesse ambiente, é pertinente que essa instituição crie condições, independentemente das diferenças, para que todas as pessoas possam apresentar, e tenham, condições de se desenvolverem nesse espaço.

\section{Legislações federais da educação superior: do ingresso à conclusão}

A Convenção sobre os Direitos das Pessoas com Deficiência (BRASIL, 2009) estabelece que os Estados-Partes devem assegurar um sistema de educação inclusiva em todos os níveis de ensino. Frente a essa convenção, assinada pelo Brasil, pergunta-se: como isso é possível?

A organização das IES para atender às demandas advindas dos processos de inclusão é assegurada a partir da criação dos cursos de graduação. Assim, a Portaria ${ }^{0}$ 1.679, de 2 de dezembro de 1999 (BRASIL,1999), e a Portaria $n^{0} 3.284$, de 7 de novembro de 2003 (BRASIL, 2003), instruem os processos de autorização, reconhecimento de cursos e credenciamento de instituições. Nesse sentido, destaca-se o artigo $1^{\circ}$, o qual dispõe que tais procedimentos devem estar “[...] conforme as normas em vigor, requisitos de acessibilidade de pessoas público-alvo da educação especial”.

As portarias supracitadas orientam sobre a organização das instituições para que sejam reconhecidas, credenciadas e autorizadas para funcionar. Apontam também, nesse viés, para a necessidade de atender às demandas de acessibilidade do público-alvo da Educação Especial.

Outro documento que trata da organização institucional do Ensino Superior para atender o público em questão é o Aviso circular nº 277 (BRASIL, 1996, p. 1), o qual foi organizado pelo Ministério da Educação e Cultura (MEC). Tal documento foi direcionado aos reitores das IES, cuja finalidade era orientá-los à adequação de suas instituições, com uma proposta inclusiva, visando garantir o acesso/ingresso do público-alvo da Educação Especial. Nesse sentido, cabe aos reitores, consoante o documento, providenciar recursos específicos de acordo com as características do estudante, como “[...] recursos e 
equipamentos específicos para cegos: provas orais e/ou em Braille, [...] intérprete no caso de Língua de Sinais no processo de avaliação dos candidatos surdos [...]”.

A Lei $n^{\circ}$ 9.394, de 20 de dezembro de 1996 (BRASIL, 1996), alterada pela Lei $n^{0}$ 13.234, de 29 de dezembro de 2015 (BRASIL, 2015, p. 1) art. 59-A, discorre que o poder público deve instituir cadastro nacional de alunos com altas habilidades/superdotação “[...] matriculados na educação básica e na educação superior, a fim de fomentar a execução de políticas públicas destinadas ao desenvolvimento pleno das potencialidades desse alunado”. Portanto, essa legislação oferta enfoque às pessoas que possuem altas habilidades/superdotação, possibilitando desenvolver ainda mais as potencialidades, aliado ao suporte das suas necessidades.

Já o Decreto $n^{\circ}$ 3.298, de 20 de dezembro de 1999 (BRASIL, 1999), apresentou discussões voltadas à garantia de permanência do público-alvo da Educação Especial no Ensino Superior. Cabe destacar que o artigo 27, que orienta as Instituições de Ensino Superior a se adequarem, por meio de adaptações, apoios considerando as características do público-alvo da Educação Especial. O movimento necessário voltado à garantia da permanência desses estudantes no Ensino Superior demanda esforços e cooperação para assegurar as condições acessíveis.

Buscando dotar as IES de condições para receber os estudantes, em 2005, foi lançado o Programa Incluir, que apresentava editais com a finalidade de apoiar projetos de criação ou reestruturação de núcleos de acessibilidade nas Instituições Federais de Ensino Superior (IFES). A criação dos núcleos favoreceu o acesso das pessoas com deficiência a todos os espaços, ambientes, ações e processos desenvolvidos nas instituições, buscando integrar e articular as demais atividades à inclusão educacional e social dessas pessoas. A acessibilidade na Educação Superior, em vista disso, foi implementada por meio do Programa Incluir, sendo concretizada pela Portaria Normativa ME $\mathrm{n}^{\circ} 14$, de 24 de abril de 2007, concebida pelo MEC, pela Secretaria da Educação Superior (SESu) e pela Secretaria da Educação Continuada, Alfabetização, Diversidade e Inclusão (SECADI), visando a ampliação e a promoção das políticas sobre acessibilidade nas IFES. A criação desses núcleos nessas instituições tem sido suporte na busca pela inclusão do Professor de Apoio Educacional Especializado (PAEE) nesses espaços (BRASIL, 2007).

O Programa Incluir foi implementado até 2011, por meio de Chamadas Públicas, em que as IFES apresentavam projetos de criação e consolidação dos Núcleos de Acessibilidade, sendo realizadas pela Secretaria de Educação Especial (SEESP) e Secretaria de Educação Superior (SESu). Em 2012, o Ministério da Educação passa a apoiar projetos das IFES, por meio da SECADI e da SESu, “com aporte de recurso financeiro, diretamente, previsto na matriz orçamentária das instituições, com a finalidade de institucionalizar ações de política de acessibilidade na educação superior, por meio dos Núcleos de Acessibilidade” (BRASIL, 2013, p. 13). Cabe ressaltar as ações desenvolvidas 
nos núcleos que visam a eliminação de barreiras físicas, pedagógicas, em materiais didáticos, comunicações e informações, ambientes, instalações e equipamentos (BRASIL, 2013).

Conforme Maciel e Anache (2017), após a implantação do programa Incluir, as universidades ampliaram as ações de permanência dos estudantes com deficiência nas IES. Essas ações, entretanto, também têm como fonte de financiamento e incentivo outras políticas de ações afirmativas. Para as autoras, o Programa foi importante para as IES, todavia há outros percalços que impedem a permanência e a conclusão do curso por parte desses estudantes.

O governo não dialogou com a comunidade acadêmica sobre a inclusão das pessoas com deficiência e suas reais necessidades; o programa não considerou as especificidades das pessoas com deficiência, nem as universidades receberam formação para a implantação dos núcleos; não considerou as iniciativas existentes em algumas IES; não contemplou todas as IES do país, apenas as públicas federais, sendo que os maiores programas de acesso e permanência como o FIES e o PROUNI são para as privadas; os professores não foram capacitados para receber esses novos acadêmicos, pois a maioria não desenvolve programas ou projetos de apoio a estes; o financiamento do governo é insuficiente (MACIEL; ANACHE, 2017, p. 84).

No tocante ao Programa Incluir, instituído pelo Governo Lula, apesar de não ter força de lei, foi um Programa que teve uma adesão significativa das IES, pois instigou o desenvolvimento de legislações voltadas às pessoas com deficiência ou àquelas com necessidades educacionais especiais, fortalecendo decretos e resoluções.

Vale referir que os programas são desenvolvidos com uma organização temporal, como programas ou até mesmo políticas de Governo e, muitas vezes, para colocar em prática as legislações. Já as leis servem para estabelecer regras e normas que devem ser seguidas para o andamento de uma sociedade. Logo, elas têm propósitos diferentes, mas que se imbricam, a partir de objetos e objetivos muitas vezes comuns.

Os Núcleos de Acessibilidade nas universidades podem ser considerados como locais com estrutura física e de pessoal, que oferecem apoio e suporte para as ações inclusivas direcionadas ao público-alvo da Educação Especial. Entre essas ações, voltadas à minimização dos efeitos das barreiras oriundas da sociedade, estão os núcleos que ofertam os serviços de "tradutor e intérprete de Língua Brasileira de Sinais, guia intérprete, equipamentos de tecnologia assistiva e materiais pedagógicos acessíveis, atendendo às necessidades dos estudantes (BRASIL, 2013, p. 21).

Autores se debruçaram sobre as temáticas da acessibilidade para refletir sobre os núcleos. Vestena e Pavão (2017) se dedicaram a identificar a formação dos profissionais que vêm atuando nos núcleos, considerando a importância da qualificação para atuar nesses espaços, a fim de garantir que as ações sejam efetivamente inclusivas. Bortolazzo e Pavão (2015) realizaram um levantamento do número de núcleos de acessibilidade existentes no Brasil, em vista das contribuições das ações desenvolvidas nesse espaço. Goularte e 
Lunardi-Lazzarin (2017) também enfatizam a importância dos núcleos dentro das universidades, pois, por meio deles, criam-se condições acessíveis.

No que se refere aos recursos ofertados para o ensino do público em pauta, ressalto: o decreto $n^{\circ}$ 5.626, de 22 de dezembro de 2005 (BRASIL, 2005), regulamenta a Lei ${ }^{\circ}$ 10.436, de 24 de abril de 2002 (BRASIL, 2002), que dispõe sobre a Língua Brasileira de Sinais (Libras); e o artigo $18^{\circ}$ da Lei $n^{\circ}$ 10.098, de 19 de dezembro de 2000 (BRASIL, 2000), possibilita ao público-alvo da Educação Especial, especificamente aqueles com surdez e que usam a Libras como meio de comunicação, a fim de que possam ter acesso a essa modalidade de comunicação dentro da IES, garantindo, assim, uma melhor interação com o meio. Sobre o acesso a esse recurso, destaca-se o art. 14: “[...] acesso à comunicação, à informação e à educação nos processos seletivos, nas atividades e nos conteúdos curriculares desenvolvidos em todos os níveis [...]”. A Libras, além de funcionar como recurso comunicacional, também deve fazer parte da matriz curricular dos cursos que formam licenciados, como se confirma no artigo $10^{\circ}$ “[...] a Libras como objeto de ensino, pesquisa e extensão nos cursos de formação de professores para a Educação Básica, nos cursos de Fonoaudiologia e nos cursos de Tradução e Interpretação de Libras - Língua Portuguesa”.

Além da criação dos núcleos mencionados, os quais subsidiaram por meio de recursos humanos as condições de acessibilidade, em 2007, foi estabelecido o Plano Nacional de Educação em Direitos Humanos (PNEDH). Esse plano tem como objetivo traçar estratégias a serem seguidas para alcançar os propósitos, ou seja, é um compilado de ações a serem atingidas. O PNEDH (BRASIL, 2007, p. 41) apontava, como estratégia para garantir a inclusão do público-alvo da Educação Especial no Ensino Superior, a adoção de “[...] políticas estratégicas de ações afirmativas nas IES que possibilitem a inclusão, o acesso e a permanência de pessoas com deficiência [...]”. Esse Plano colocava a necessidade de intensificar o desenvolvimento de políticas que pudessem ampliar a discussão sobre práticas inclusivas na Educação Superior, a fim de garantir ao público-alvo da Educação Especial que conseguissem acessar, permanecer e concluir o curso desejado de forma qualitativa. Nesse sentido, o acesso à universidade não corresponde apenas ao ingresso, mas à permanência desse aluno na instituição, com "subsídios que garantam condições adequadas para a conclusão com sucesso do curso” (CASTRO; ALMEIDA, 2014, p. 180).

Documentos internacionais ofertam suporte para as ações voltadas ao ingresso, definindo as responsabilidades pela adoção de estratégias para tal. O Decreto $n^{\circ}$ 6.949, de 25 de agosto de 2009 (BRASIL, 2009), que promulga a Convenção Internacional sobre os Direitos das Pessoas com Deficiência e seu Protocolo Facultativo, assinados em Nova York em 30 de março de 2007, aponta que a responsabilidade legal pela garantia de acesso ao Ensino Superior do público-alvo da Educação Especial é dos Estados Partes. Esses 
“assegurarão que as pessoas com deficiência possam ter acesso ao ensino superior em geral [...]”, providenciando as ações necessárias, visando a inclusão nesse nível de ensino.

O decreto mencionado foi importante, pois desencadeou discussões sobre a inclusão na Educação Superior. Assim, contribuiu para a criação de legislações e políticas públicas que buscassem garantir uma melhor qualidade de vida às pessoas público-alvo da educação especial, por meio da eliminação de barreiras (física, pedagógica, dentre outras) também nas IES.

Garantido o ingresso, há necessidade de criar estratégias para a permanência e conclusão dos cursos. Desse modo, o Decreto n ${ }^{0}$ 7.234, de 19 de julho de 2010 (BRASIL, 2010), que dispõe sobre o Programa Nacional de Assistência Estudantil (PNAES) foi desenvolvido em articulação com as atividades de ensino, pesquisa e extensão, visando o atendimento de estudantes regularmente matriculados em cursos de graduação presencial das IFES. No que se refere ao público-alvo da Educação Especial, destaca-se: art. $3^{\circ}$, parágrafo $1^{\circ}$, inciso “ $X$ - acesso, participação e aprendizagem de estudantes com deficiência, transtornos globais do desenvolvimento e altas habilidades e superdotação”.

Ainda em 2010, um livro publicado pela Secretaria Nacional de Educação Especial, Diversidade e Inclusão argumentava sobre a importância da efetivação de estratégias de educação especial na Educação Superior, através de ações para o acesso, a permanência e a participação dos estudantes nas universidades. Ademais, reiterava a importância de planejamento e organização de recursos e serviços que possibilitassem acessibilidade arquitetônica nas IES, bem como nas comunicações, nos sistemas e nos materiais didáticos utilizados e disponibilizados pelos docentes (BRASIL, 2010). Passados dez anos, outros autores ainda enfatizam essa necessidade (CHRISTMANN, 2019).

Como direito garantido pela legislação, as IES devem propiciar ao público-alvo da Educação Especial as adequações necessárias para sua inclusão no nível de ensino em questão. Nesse sentido, destaca-se o artigo 27º da Lei $n^{\circ} 13.146$ (BRASIL, 2015), que “assegura sistema educacional inclusivo em todos os níveis e aprendizado ao longo de toda vida [...]”. Também, salienta-se o artigo $30^{\circ}$ da referida lei, que pontua sobre ações necessárias para garantir o acesso e a permanência do público-alvo da Educação Especial no Ensino Superior. Entre essas ações, está incluído o atendimento preferencial, disposição de materiais adaptados, apoio especializado, flexibilização pedagógica, além de outras adequações. Para que o público-alvo da Educação Especial tenha a possibilidade de ingressar numa instituição de Ensino Superior, faz-se necessário o provimento de ações inclusivas acessíveis e adequadas às características do estudante, para que, realmente, ele possa ter a chance de ingressar na instituição e concluir o curso.

Apesar de os documentos supracitados apontarem para a educação como direito do público em pauta, ofertando, por meio de diferentes ações/condições de aprendizagem, o acesso ao Ensino Superior dessas pessoas só foi garantido pela Lei $\mathrm{n}^{0} 13.409$, de 28 de dezembro de 2016 (BRASIL, 2016). Em seu artigo $3^{\circ}$, refere que as IFES devem dispor de 
um percentual de vagas para as pessoas com deficiência, também estabelecendo um prazo de 10 anos para as instituições se adequarem às propostas inclusivas, organizando-se para garantir que o público em comento possa ter acesso, consiga permanecer e concluir o curso de forma qualitativa.

Outro aspecto importante a ser referenciado, considerando as particularidades desse público, o qual exige um olhar mais aprofundado e cuidadoso com os estudantes, visando a permanência no Ensino Superior, trata do apoio pedagógico de profissionais com formação específica (em Educação Especial). Nesse sentido, esses profissionais “atuam de forma a colaborar nos processos, favorecendo as igualdades de oportunidades de acesso ao conhecimento” (RAMPELOTTO; LINASSI; MELARA, 2016, p. 7). No que diz respeito à formação para atuar frente a esse público, não há qualquer orientação direcionada aos docentes da Educação Superior, apenas aos da Educação Básica. Sobre essa formação em documentos legais, as orientações aparecem de forma sucinta e genérica, como consta na Resolução no 4/2009 (BRASIL, 2009), art. 1: "o professor deve ter formação inicial que o habilite para o exercício da docência e a formação específica para a Educação Especial”.

O professor da Educação Especial assume posição central no cenário educacional inclusivo, pois juntamente com os demais profissionais que compõem a instituição de ensino, tem a função de mediador didático, orientador e mobilizador de recursos de caráter inclusivo. Tal profissional possui múltiplas funções, pois orienta profissionais e familiares a assumirem uma postura mais inclusiva. Além disso, esse profissional oferta o Atendimento Educacional Especializado (AEE), voltado à atenção individualizada ao discente e que atua colaborando no processo de ensino e aprendizagem dos estudantes (TEZZARI, 2009; BRASIL, 2009).

O profissional da Educação Especial pode contribuir qualitativamente no processo de ensino e aprendizagem do público-alvo da Educação Especial, visto que possui uma gama de conhecimentos sobre as características que podem ser apresentadas pelas pessoas, além de conhecimentos pedagógicos apropriados à demanda desses estudantes. Pensando nessa multiplicidade de características apresentadas pelo público-alvo da Educação Especial, é imprescindível investir em profissionais qualificados e capacitados. Atualmente, observa-se a necessidade de intensificar e expandir cursos voltados à qualificação dos professores para atuar com o público em questão, objetivando sua inclusão. Contudo, cabe ressaltar que "a formação não se constrói por acumulação (de cursos, de conhecimentos e de técnicas), mas sim através de um trabalho de reflexividade crítica sobre as práticas de re(construção) permanente” (NÓVOA, 1992, p. 25).

No Brasil, em relação à formação inicial - licenciatura (Educação Especial) a nível de graduação -, se destacam duas instituições, consideradas pioneiras nessa formação. São elas: a Universidade Federal de Santa Maria (UFSM), localizada em Santa Maria, estado do Rio Grande do Sul, que possui três cursos de Licenciatura em Educação Especial com 
currículos voltados a práticas inclusivas; ${ }^{4}$ e a Universidade Federal de São Carlos, localizada em São Carlos, estado de São Paulo, ${ }^{5}$ ofertando, além da graduação, cursos de mestrado e doutorado com linhas de pesquisas voltadas para a Educação Especial e Educação Inclusiva. Vale referir que essas são as IES mais antigas, entretanto existem no total 43 cursos $^{6}$ de licenciatura em Educação Especial no país, sendo 25 de nível presencial e 18 cursos EAD, segundo dados do E-MEC (BRASIL, 2019).

Vale referenciar a importância dos profissionais da Educação Especial, não apenas para os processos que envolvem estar na universidade, mas também para os professores em geral, de modo que eles se sintam parte integrante do processo de inclusão e formação dos estudantes como seres humanos e profissionais capacitados. Portanto, o investimento em cursos de capacitação e a conscientização sobre a necessidade dessa capacitação se fazem pertinentes entre os docentes. Por fim, garantir o acesso e a conclusão do curso de forma qualitativa no Ensino Superior é de competência das instituições, e envolve diferentes aspectos a serem considerados. Essas instituições devem mobilizar uma rede de esforços, considerando as características individuais de seus alunos.

\section{Considerações finais}

Realizou-se um mapeamento de documentos normativos que visam garantir a inclusão e a permanência do público-alvo da Educação Especial no Ensino Superior. Evidencia-se que as discussões legais, isto é, os documentos que orientam as práticas inclusivas no Ensino Superior ainda são incipientes se comparados aos direcionados à Educação Básica. Cabe ressaltar a transversalidade da educação especial aos demais níveis e modalidade de ensino, isto é, desde a Educação Infantil até a Educação Superior, oferta de Atendimento educacional especializado e a continuidade da escolarização nos níveis mais elevados do ensino (BRASIL, 2008).

Os documentos que buscam orientar e regular a Educação Especial no contexto da Educação Superior, parecem, ainda, não serem suficientes para abranger a complexidade que envolve a efetividade do processo de aprender. Essa afirmação se faz, especialmente, em relação à Educação Superior, em que as áreas de conhecimentos, podem vir a exigir aprendizagens muito específicas, além de apoio pedagógico.

Muito já se evoluiu, principalmente depois no Programa Incluir. Contudo, atualmente, a lei que trata da Educação como um direito da pessoa com deficiência, reservando vagas em IES e buscando garantir equidade, integralidade e qualidade na permanência e conclusão é a Lei no 13.409/16 (BRASIL, 2016). Já a Política de Educação

${ }^{4}$ Na Universidade Federal de Santa Maria: Licenciatura em Educação Especial Diurno - Código n ${ }^{\circ}$ 633. Licenciatura em Educação Especial Noturno - Código no ${ }^{\circ}$ 637. Licenciatura em Educação Especial EAD - Código n ${ }^{\circ} 639$.

${ }^{5}$ Licenciatura em Educação Especial (UFScar) - Código No 115102.

${ }^{6}$ Consulta realizada em 19 de junho de 2019, junto ao endereço do Ministério da Educação, disponível em: http://emec.mec.gov.br/. 
Especial na Perspectiva da Educação Inclusiva (BRASIL, 2008), aponta a transversalidade da Educação Especial na Educação Superior. Os demais documentos analisados não trazem orientações específicas; apenas com sua interpretação, vislumbra-se subsídios para repensar tal temática.

Diante disso, em decorrência da inserção do público-alvo da Educação Especial no Ensino Superior, sente-se a necessidade de documentos legais específicos que possam orientar sobre a inclusão nesse nível de ensino, ofertando base legal para a criação de estratégias e ações para a permanência, que venham a favorecer a conclusão dos cursos por essas pessoas, bem como a destinação de recursos financeiros para o desenvolvimento das ações abordadas.

Cabe destacar os discursos presentes nos documentos legais discutidos, a fim de garantir práticas inclusivas no Ensino Superior. Esses documentos apontam a necessidade de fazer uso de instrumentos apropriados às características do estudante. Portanto, as Instituições de Ensino Superior, ao se instrumentalizarem, de forma a dar suporte e atender as demandas do estudante, atenderão ao preconizado pela documentação legal. Entretanto, isso será possível frente à realidade socioeconômica brasileira? Surgem assim, outros questionamentos que suscitam novos estudos.

Por fim, o artigo apresentou os documentos legais existentes, porém sinaliza a necessidade de ampliação. Esta só será possível se os movimentos em prol de direitos humanos, como também da educação para todos, continuarem existindo e se fortalecendo, bem como o desenvolvimento de pesquisas da área que demonstrem essa necessidade e as possibilidades advindas desse investimento.

\section{Referências}

APA - AMERICAN PSYCHIATRIC ASSOCIATION. Manual Diagnóstico e Estatístico de Transtornos Mentais: DSM-5. 5. ed. Porto Alegre: Artmed: 2013.

BARDIN, Laurence. Análise de Conteúdo. Lisboa: Edições 70, LDA, 2011.

BORTOLAZZO, Jéssica; PAVÃO, Sílvia Maria de Oliveira. Aprendizagem e acessibilidade na educação superior. In: PAVÃO, Sílvia Maria de Oliveira (Org.). Ações de atenção à aprendizagem no ensino superior. 1. ed. Santa Maria: UFSM, PRE, Ed. pE.com, 2015. p. 210.

BRASIL. Ministério da Educação. Lei de Diretrizes e Bases da Educação Nacional, LDB 4.024, de 20 de dezembro de 1961. Brasília: DOU, 1961.

BRASIL. Ministério da Educação. Secretaria de Educação Especial. Política Nacional de Educação Especial. Brasília: MEC/SEESP, 1994. Brasília: DOU, 1994.

BRASIL. Ministério da Educação. Aviso Circular n 277/MEC/GM. 1996. Brasília: DOU, 1996. Disponível em: http://portal.mec.gov.br/seesp/arquivos/pdf/aviso277.pdf. Acesso em: 10 mar. 2018.

BRASIL. Ministério da Educação. Lei de Diretrizes e Bases da Educação Nacional, LDB 9.394, de 20 de dezembro de 1996. Brasília: DOU, 1996. 
BRASIL. Decreto $n^{\circ}$ 3.298, de 20 de dezembro de 1999. Regulamenta a Lei $n^{\circ} 7.853$, de 24 de outubro de 1989, dispõe sobre a Política Nacional para a Integração da Pessoa Portadora de Deficiência, consolida as normas de proteção, e dá outras providências. Brasília: DOU, 1999. Disponível em: http://www.planalto.gov.br/ccivil_03/decreto/D3298.htm. Acesso em: 01 out. 2018.

BRASIL. Ministério da Educação. Portaria $n^{\circ}$ 1.679, de 2 de dezembro de 1999. Dispõe sobre requisitos de acessibilidade de pessoas portadoras de deficiências, para instruir os processos de autorização e de reconhecimento de cursos, e de credenciamento de instituições. Brasília: $\quad$ DOU, $1999 . \quad$ Disponível em: http://portal.mec.gov.br/sesu/arquivos/pdf/c1_1679.pdf. Acesso em: 23 mar. 2018.

BRASIL. Ministério da Educação. Secretaria de Educação Especial. Lei $n^{\circ}$. 10.436, de 24 de abril de 2002. Dispõe sobre a Língua Brasileira de Sinais - Libras - e dá outras providências. Brasília: DOU, 2002.

BRASIL. Ministério da Educação. Portaria $n^{\circ}$ 2.678, de 24 de setembro de 2002. Brasília: DOU, 2002. Disponível em: https://www.fnde.gov.br/acesso-ainformacao/institucional/legislacao/item/3494-portaria-mec-n\%C2\%BA-2678-de-24-desetembro-de-2002. Acesso em: 24 jun. 2019.

BRASIL. Portaria $n^{\circ} 3.284$, de 7 de novembro de 2003. Dispõe sobre requisitos de acessibilidade de pessoas portadoras de deficiências, para instruir os processos de autorização e de reconhecimento de cursos, e de credenciamento de instituições. Brasília: DOU, 2003. Disponível em: http://portal.mec.gov.br/seesp/arquivos/pdf/port3284.pdf. Acesso em: 01 out. 2018.

BRASIL. Ministério da Educação. Secretaria de Educação Especial. Decreto $n^{\circ}$ 5.296, de 02 de dezembro de 2004. Regulamenta as Leis $\mathrm{n}^{0} 10.048$, de 8 de novembro de 2000, que dá prioridade de atendimento às pessoas que especifica, e 10.098, de 19 de dezembro de 2000, que estabelece normas gerais e critérios básicos para a promoção da acessibilidade das pessoas portadoras de deficiência ou com mobilidade reduzida, e dá outras providências. Brasília: DOU, 2004. Disponível em: http://portal.mec.gov.br/seesp/arquivos/pdf/decreto\%205296-2004.pdf. Acesso em: 24 jun. 2019.

BRASIL. Decreto 5.626, de 22 de dezembro de 2005. Regulamenta a Lei no 10.436, de 24 de abril de 2002, que dispõe sobre a Língua Brasileira de Sinais - Libras, e o art. 18 da Lei $\mathrm{n}^{\circ}$ 10.098, de 19 de dezembro de 2000. Brasília: DOU, 2005. Disponível em: http://www.planalto.gov.br/ccivil_03/_Ato2004-2006/2005/Decreto/D5626.htm. Acesso em: 01 out. 2018.

BRASIL. Lei $n^{\circ} 11.096$, de 13 de janeiro de 2005. Institui o Programa Universidade para Todos - PROUNI, regula a atuação de entidades beneficentes de assistência social no ensino superior; altera a Lei $n^{0} 10.891$, de 9 de julho de 2004, e dá outras providências. Brasília: DOU, 2005. Disponível em: http://www.planalto.gov.br/ccivil_03/_Ato20042006/2005/Lei/L11096.htm. Acesso em: 24 jun. 2019.

BRASIL. Ministério da Educação. Portaria Normativa $n^{\circ}$ 14, de 24 de abril de 2007. Dispõe sobre a criação do "Programa Incluir: Acessibilidade na Educação Superior". Brasília: 2007. DOU, Disponível em: http://portal.mec.gov.br/arquivos/pdf/programa_incluir.pdf. Acesso em: 25 mar. 2018.

BRASIL. Comitê Nacional de Educação em Direitos Humanos. Plano Nacional de Educação em Direitos Humanos. Comitê Nacional de Educação em Direitos Humanos. Brasília: Secretaria Especial dos Direitos Humanos, Ministério da Educação, Ministério da Justiça, UNESCO, 2007.

BRASIL. Ministério da Educação. Secretaria de Educação Especial. Política Nacional de Educação Especial na Perspectiva da Educação Inclusiva. Brasília: MEC/SEESP, 2008.

BRASIL. Ministério da Educação. Resolução $n^{o}$ 4, de outubro de 2009. Institui Diretrizes Operacionais para o Atendimento o Educacional Especializado na Educação Básica, 
modalidade Educação Especial. Brasília: DOU, 2009. Disponível em: http://portal.mec.gov.br/dmdocuments/rceb004_09. Acesso em: 24 ago. 2018.

BRASIL. Ministério da Educação. Secretaria de Educação Especial. Decreto $n^{\circ}$ 6.949, de 25 de agosto de 2009. Promulga a Convenção Internacional sobre os Direitos das Pessoas com Deficiência e seu Protocolo Facultativo, assinados em Nova York, em 30 de março de 2007. Brasília: 2009. DOU, Disponível em: http://portal.mec.gov.br/dmdocuments/decreto6949_seesp.pdf. Acesso em: 16 mar. 2018.

BRASIL. Ministério da Educação. Secretaria de Educação Especial. Marcos PolíticoLegais da Educação Especial na Perspectiva da Educação Inclusiva. Secretaria de Educação Especial. Brasília: Secretaria de Educação Especial, 2010. 73 p. ISBN 978-8560331-28-4.

BRASIL. Decreto $n^{\circ}$ 7. 234, de 19 de julho de 2010. Dispõe sobre o Programa Nacional de Assistência Estudantil - PNAES. Brasília: DOU, 2010. Disponível em: http://www.planalto.gov.br/ccivil_03/_Ato2007-2010/2010/Decreto/D7234.htm. Acesso em: 15 out. 2018.

BRASIL. Ministério da Educação. Programa de Acessibilidade na Educação Superior (Incluir). Brasília: $2013 . \quad$ MEC, Disponível em: http://portal.mec.gov.br/index.php?option=com_docman\&view=download\&alias=12737documento-orientador-programa-incluir-pdf\&category_slug=marco-2013-pdf\&Itemid=301 92. Acesso em: 23 mar. 2018.

BRASIL. Lei $n^{\circ}$ 13.146, de 6 de julho de 2015. Institui a Lei Brasileira de Inclusão da Pessoa com Deficiência (Estatuto da Pessoa com Deficiência). Brasília: DOU, 2015. Disponível em: http:/www.planalto.gov.br/ccivil_03/_ato2015-2018/2015/lei/l13146.htm. Acesso em: 24 mar. 2018.

BRASIL. Lei $n^{\circ}$ 13.234, de 29 de dezembro de 2015. Altera a Lei $n^{\circ}$ 9.394, de 20 de dezembro de 1996 (Lei de Diretrizes e Bases da Educação Nacional), para dispor sobre a identificação, o cadastramento e o atendimento, na educação básica e na educação superior, de alunos com altas habilidades ou superdotação. Brasília: DOU, 2015. Disponível em: http://www.planalto.gov.br/ccivil_03/_Ato2015-2018/2015/Lei/L13234.htm\#art2. Acesso em: 19 jun. 2019.

BRASIL. Lei $n^{\circ}$ 13.409, de 28 de dezembro de 2016. Altera a Lei $n^{\circ} 12.711$, de 29 de agosto de 2012, para dispor sobre a reserva de vagas para pessoas com deficiência nos cursos técnico de nível médio e superior das instituições federais de ensino. Brasília: DOU, 2016. Disponível em: http://www.planalto.gov.br/ccivil_03/_ato20152018/2016/lei/L13409.html. Acesso em: 20 maio 2018.

BRASIL. Ministério da Educação. Cadastro Nacional de Cursos e Instituições de Educação Superior. Cadastro e-MEC: Educação Especial. [s.d.] Disponível em: http://emec.mec.gov.br/. Acesso em: 19 jun. 2019.

CASTRO, Sabrina Fernandes.; ALMEIDA, Maria Amelia. Ingresso e Permanência de alunos com deficiência em universidades públicas. Revista Brasileira de Educação Especial, Marília, v. 20, n. 2, p. 179-194, abr./jun. 2014.

CHRISTMANN, Morgana. Concepções docentes sobre saúde e deficiência sob o prisma da Teoria bioecológica de desenvolvimento humano. Doutorado em Educação (Tese) Universidade Federal de Santa Maria, 2019. 253 p.

DINIZ, Maria Helena. Curso de direito civil brasileiro. 29. ed. São Paulo: Saraiva, 2012. v. 1 .

GOULARTE, Ravele Bueno; LUNARDI-LAZZARIN, Marcia Lise. Ações de uma universidade acessível/inclusiva. In: FIORIN, Bruna Alves; PAVÃO, Sílvia Maria de Oliveira (Org.) Educação superior: desafios para a não compartimentação dos saberes. Santa Maria: Facos-UFSM, 2017. p. 90-99. 
JANUZZI, Gilberta M. A educação do deficiente no Brasil: dos primórdios ao início do século XXI. Campinas, SP: Autores Associados, 2004.

MACIEL, Carina Elisabeth; ANACHE, Alexandra Ayach. A permanência de estudantes com deficiência nas universidades brasileiras. Educar em Revista, v. 33, n. especial, p. 7186, dez. 2017. Disponível em: http://revistas.ufpr.br/educar/article/view/52924/34098. Acesso em: 05 dez.2017.

MOLINA, Adão Aparecido; RODRIGUES, Adriana Aparecida Rodrigues. Estado, Políticas Públicas e Formação Docente no Brasil: direcionamentos a partir do início do século XXI. Ensino em Re-vista, v. 1, p. 40-67, fev. 2020.

NOVOA, Antonio. Os professores e a sua formação. Lisboa: Publicações Dom Quixote, 1992.

OMS - ORGANIZAÇÃO MUNDIAL DE SAÚDE. Direção Geral de Saúde. Classificação Internacional de Funcionalidade Incapacidade e Saúde (CIF). Lisboa, PT: 2004. Disponível em: http://www.inr.pt/uploads/docs/cif/CIF_port_\%202004.pdf. Acesso em: 24 mar. 2017.

PEREIRA, Cíntia Beatriz Duarte Pereira. Políticas públicas de inclusão: desafios e benefícios da implementação da política de cotas para deficientes nas universidades federais. ECCOM, v. 11, n 21, p.179-187, jan. 2020.

PIMENTA, Selma Garrido; ANASTASIOU, Léa das Graças Camargos. Docência no Ensino Superior. 5. ed. São Paulo: Cortez, 2014.

PRODANOV, Cleber Cristiano; FREITAS, Ernani Cesar. Metodologia do Trabalho Científico: Métodos e Técnicas da Pesquisa e do Trabalho Acadêmico. 2. ed. Novo Hamburgo: Feevale, 2013.

RAMPELLOTO, Elisiane Maria; LINASSI, Priscila.; MELARA, Adriane. O profissional da educação especial e sua atuação no ensino superior reflexões sobre as políticas públicas. In: SEMINÁRIO NACIONAL DE PESQUISA EM EDUCAÇÃO, 6., 2016, Santa Cruz do Sul. Anais... Santa Cruz do Sul: EDUNISC, 2016. p. 1-13.

RUA, Maria das Graças. Análise de Políticas Públicas: Conceitos Básicos. In: RUA, Maria das Graças; VALADAO, Maria Izabel. O Estudo da Política: Temas Selecionados. Brasília: Paralelo 15, 1998.

SASSAKI, Romeu Kazumi. Inclusão: o paradigma do século 21. Revista Inclusão, ano I, n. 1, p. 19-23, out., 2005.

SECCHI, Leonardo. Políticas Públicas: conceitos, esquemas de análises, casos práticos. São Paulo: CENGAGE Learning, 2012.

SCHIMDT, Carlo et al. Inclusão escolar e autismo: uma análise da percepção docente e práticas pedagógicas. Revista Psicologia: Teoria e Prática, São Paulo, v. 18, n. 1, p. 222 235, jan./abr., 2016. Disponível em: http://w3.ufsm.br/edea/images/ARTIGOS/935738518-2-PB.pdf. Acesso em: 19 jun. 2019.

SCHIMDT, Carlo. Transtorno do Espectro Autista: Onde estamos e para onde vamos. Psicologia em Estudo, Maringá, v. 22, n. 2, p. 221-230, abr./jun. 2017. Disponível em: http://www.periodicos.uem.br/ojs/index.php/PsicolEstud/article/view/34651. Acesso em: 19 jun. 2019.

SOUSA, Harley Gomes de; SILVA, Graça Maria de Moraes Aguiar. Política e Legislação da Educação. Sobral: INTA, 2016. Disponível em: http://md.intaead.com.br/geral/politicas_e_legislacao_da_educacao/pdf/Politicas\%20Educacionais_Livro.pdf. Acesso em: 20 jun. 2019.

SOUZA, Celina. Políticas Públicas: uma revisão da literatura. Sociologias, Porto Alegre, ano 8, n. 16, p. 20-45, jul./dez. 2006. Disponível em: http://www.scielo.br/pdf/soc/n16/a03n16.Acesso em: 05 dez. 2018. 
TEZZARI, Mauren Lúcia. Educação Especial e Ação Docente: da medicina à educação. 2009. 243 f. Tese (Doutorado em Educação) - Universidade Federal do Rio Grande do Sul, Porto Alegre 2009.

TORRENS, Antonio Carlos. Poder Legislativo e políticas públicas: Uma abordagem preliminar. Revista de Informação Legislativa, ano 50, n. 197, jan./mar. 2013. Disponível em: https://www12.senado.leg.br/ril/edicoes/50/197/ril_v50_n197_p189.pdf. Acesso em: 20 jun. 2019.

VESTENA, Natana Pozzer; PAVÃO, Silvia Maria de Oliveira. A permanência do estudante com deficiência na educação superior: discutindo uma revisão. In: FIORIN, Bruna Alves; PAVÃO, Sílvia Maria de Oliveira (Org.). Educação superior: desafios para a não compartimentação dos saberes. Santa Maria: Facos-UFSM, 2017. p. 127-133.

WCEFA - World Conference on Education for All. Declaração Mundial sobre Educação para Todos. WCEFA: Jomtien, Tailândia, 1990.

Recebido em: 12/08/2019

Aprovado em: 13/04/2020 